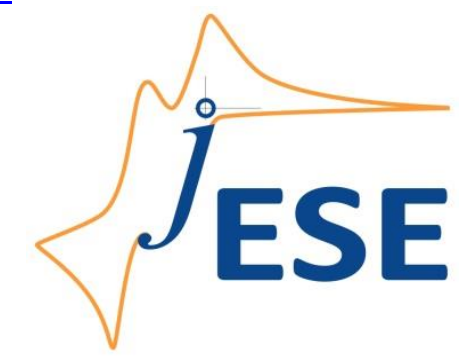

Open Access: ISSN 1847-9286

www.jESE-online.org

Original scientific paper

\title{
Staircase voltammetry of dissolved redox couple in a thin layer twin electrode cell
}

\author{
Milivoj Lovrić ${ }^{\bowtie}$
}

Divkovićeva 13, Zagreb 10090, Croatia

Corresponding author: ${ }^{凶}$ mlovric@irb.hr

Received: August 10, 2018; Accepted: September 18, 2019

\begin{abstract}
A model of reversible and quasi-reversible electrode reaction of dissolved redox couple is developed for the staircase voltammetry and the twin electrode thin layer cell. It is assumed that the neutral molecule is oxidized to a monovalent cation. The calculations were performed for the absence of supporting electrolyte and for its various concentrations. The influence of migration of cations and of $I R_{\Omega}$ drop on the peak currents and peak potentials was investigated. Also, the kinetically controlled electrode reactions were simulated. These reactions can be distinguished from the reactions influenced by the resistance in the solution.
\end{abstract}

\section{Keywords}

Steady state voltammetry; two electrodes cell; migration; theory

\section{Introduction}

There is a considerable interest in the investigation of the influence of supporting electrolyte on the mass transfer [1-4] and the charge transfer [5] on microelectrodes [6-8] and rotating disk electrodes $[9,10]$. These measurements can be also performed in the thin layer cells [11-15], particularly in those that operate without a reference electrode [16-18]. These twin electrode cells are useful for the analysis of solutions of redox couples [19-21]. In this paper, a diffusion and migration in the micrometer-type cell are simulated for the staircase voltammetry that appears in the modern digital instrumentation [22-27].

The model

An electrode reaction of a neutral compound and its cation in the twin electrode thin layer cell is investigated.

Red $\leftrightarrow \mathrm{Ox}^{+}+\mathrm{e}^{-}$ 
Initially, a solution contains equal concentrations of the compound and the salt of its cation. A certain inert electrolyte $M X$ may be also present in the solution. The solvent is polar and supports the dissociation of ionic compounds OxA and MX. The model applies, for instance, to the mixture of ferrocene and ferrocenium tetrafluoroborate [28]. As the difference between the potentials of two electrodes increases, the first electrode acts as an anode and the second one as a cathode. At the anode the compound is oxidized and at the cathode the cation is reduced. The current depends on the concentrations of ionic species $\mathrm{Ox}^{+}, \mathrm{A}^{-}, \mathrm{M}^{+}$and $\mathrm{X}^{-}$. For the sake of simplicity, it is assumed that all ionic mobilities are equal:

$$
u_{\text {ion }}=F D / R T
$$

In eq. (2), $D$ is a common diffusion coefficient. The electric potential gradient in the film depends on the ohmic resistance:

$$
\partial \psi / \partial x=I R_{\Omega} / I
$$

where $I$ is a current and $I$ is the film thickness. The resistance is estimated using the relationship between the equivalent conductivity at infinite dilution and the concentration of ions:

$$
\begin{aligned}
& R_{\Omega}=S^{-1} \int_{0}^{1} \sigma^{-1} \mathrm{~d} x \\
& \sigma=F^{2} D\left(c_{\mathrm{OX}^{+}}^{*}+c_{A^{-}}^{*}+c_{\mathrm{M}^{+}}^{*}+c_{\mathrm{X}^{-}}^{*}\right) / R T
\end{aligned}
$$

where $S$ is the electrode surface area and $c_{Y}^{*}$ is initial concentration of ions. Also, an electroneutrality in the solution is assumed.

If the electrode reaction (1) is fast and reversible, the diffusion and migration of electroactive species are defined by the following differential equations and the initial and boundary conditions:

$$
\begin{aligned}
& \partial c_{\text {Red }} / \partial t=D \partial^{2} c_{\text {Red }} / \partial x^{2} \\
& \partial c_{O x} / \partial t=D \partial^{2} c_{O x} / \partial x^{2}-u_{\text {ion }}(\partial \psi / \partial x)\left(\partial c_{O x} / \partial x\right) \\
& t=0,0 \leq x \leq I: \quad c_{O x}^{*}=c_{\text {Red }}^{*}, \Delta E=0 \\
& \mathrm{t}>0, x=0: \quad c_{O x, x=0}^{*}=c_{\text {Red, } x=0}^{*} \exp \left[F\left(E_{1}-E^{0}\right) / R T\right] \\
& E_{1}-E^{0}=\Delta E / 2-I R_{\Omega} / 2 \\
& D\left(\partial c_{\text {Red }} / \partial x\right)_{x=0}=I / F S \\
& D\left(\partial c_{O x} / \partial x\right)_{x=0}=-I / F S+u_{\text {ion }}(\partial \psi / \partial x) c_{O x, x=0} \\
& \mathrm{t}>0, x=I: \quad c_{O x, x=I}=C_{R e d, x=I} \exp \left[F\left(E_{2}-E^{0}\right) / R T\right] \\
& E_{2}-E^{0}=-\Delta E / 2+I R_{\Omega} / 2 \\
& D\left(\partial c_{\text {Red }} / \partial x\right)_{x=1}=I / F S \\
& D\left(\partial c_{O x} / \partial x\right)_{x=I}=-I / F S+u_{\text {ion }}(\partial \psi / \partial x) c_{O x, x=I}
\end{aligned}
$$

$\Delta E$ is a potential difference between two electrodes. Equations (6) and (7) are solved by the finite difference method [29]. By the combination of conditions (9) - (12) a non-linear equation for current is obtained. It appears in the form:

$$
(a+b x) \exp (d x)=p-q x-r x^{2}
$$

All parameters are positive and $a<p$. So, the solution of this equation can be found numerically, as the cross section of the exponential curve and the parabola.

The dimensionless current $\Phi$ is defined as a ratio of the current and the limiting current that appears under steady state conditions: 


$$
I_{\mathrm{ss}}=2 F S D c_{\mathrm{Red}}^{*} / I
$$

In staircase voltammetry the scan rate is defined as a ratio of the potential increment and the duration of step:

$$
v=\mathrm{d} E / \tau
$$

It was assumed that $\mathrm{d} E=1 \mathrm{mV}$ if $v \leq 1 \mathrm{~V} / \mathrm{s}$ and that $\tau=1 \mathrm{~ms}$ if $v>1 \mathrm{~V} / \mathrm{s}$. In the calculation the dimensionless diffusion coefficient $D \Delta t / \Delta x^{2}=0.4$ and the time increment $\Delta t=10^{-4} \mathrm{~s}$ were used. Also, the distance between electrodes was divided in 100 space increments.

\section{Results and discussion}

The relationship between dimensionless currents and the potential difference in the twin electrode thin layer cell in the absence of supporting electrolyte is shown in Figure 1 . All curves tend to the limit that indicates the establishment of steady state in the cell. At higher scan rates voltammograms exhibit maxima, while at lower scan rates they resemble polarographic wave.

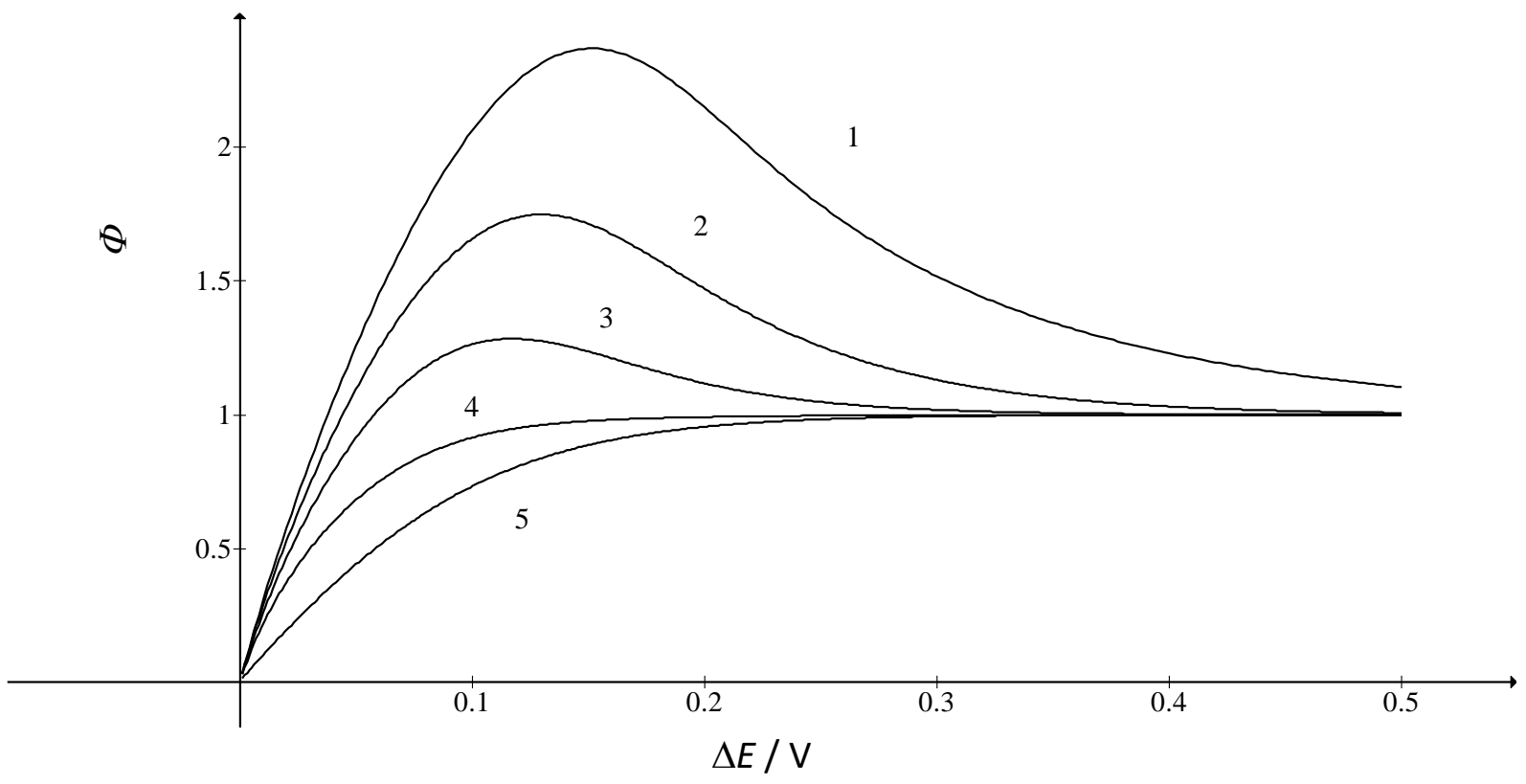

Fig. 1 Dimensionless staircase voltammograms of electrode reaction (1). $[\mathrm{MX}]^{*}=0$ and $v / \mathrm{Vs}^{-1}=2(1), 1(2), 0.5(3), 0.2(4)$ and 0.01 (5).

These characteristics are caused by the development of concentration gradients that are shown in Figure 2. At the potential difference of maximum, the diffusion layers are extended to the middle of cell, but they do not overlap. One can notice that the gradients of cation are lower than the gradients of compound, which is caused by the migration of cations.

Under steady state the gradient of compound is constant, and its concentration is defined by the equation: $c_{\text {Red }} / c_{\text {Red }}^{*}=2 x / I$. The concentration of cation is given by the equation:

$c_{\mathrm{Ox}} / c_{\mathrm{Ox}}^{*}=2-\exp (x / I) /(e-1)$

It is the solution of the differential equation:

$\mathrm{d} c_{\mathrm{Ox}} / \mathrm{d} x=-2 c_{\mathrm{Ox}}^{*} / I+c_{\mathrm{Ox}} / I$

And the boundary condition:

$\int_{0}^{l} c_{O x} d x=c_{O x}^{*} I$ 

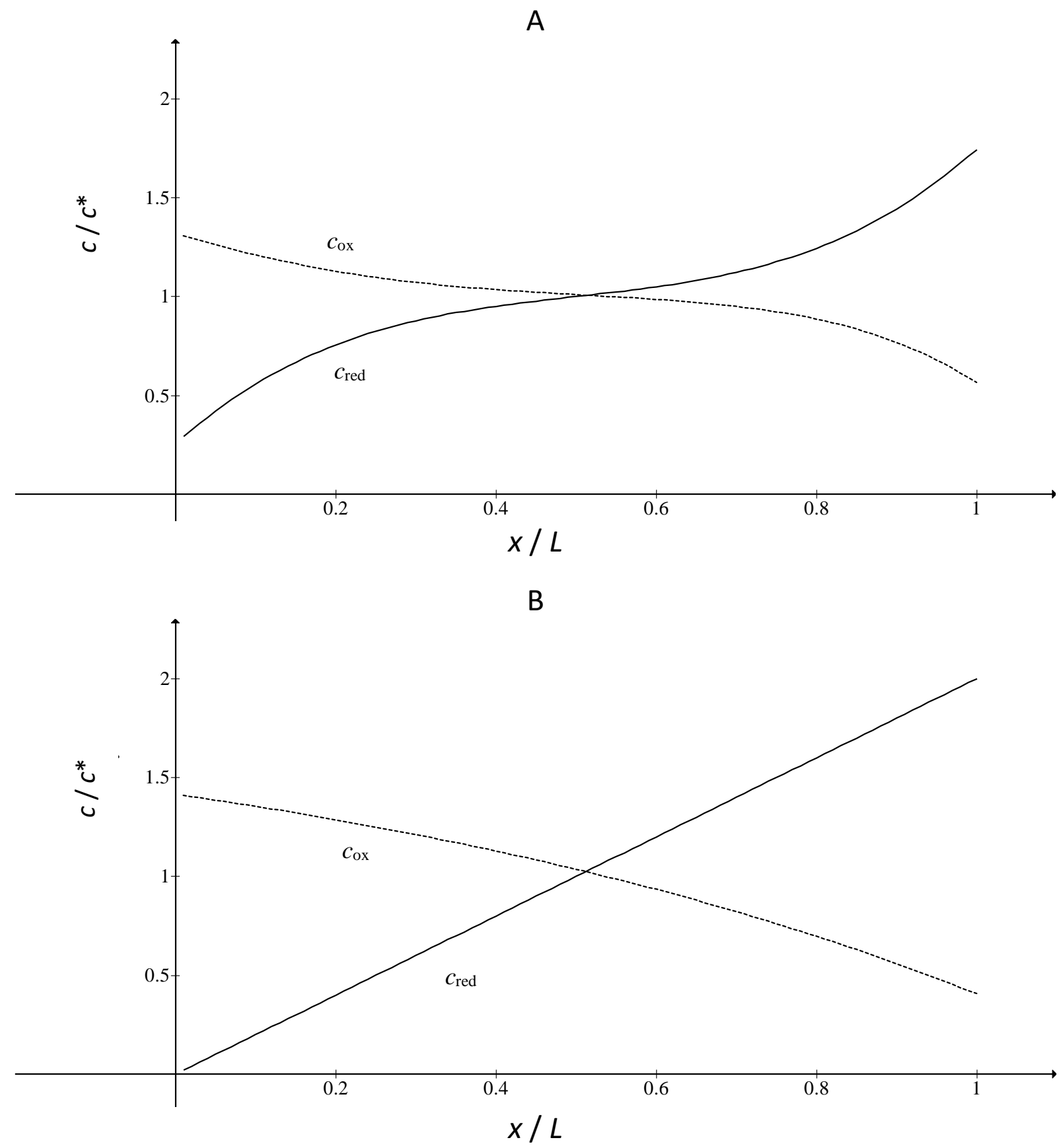

Fig. 2 Dimensionless concentrations of the reduced and oxidized components of electrode reaction (1). $[M X]^{*}=0, v=1 \mathrm{~V} / \mathrm{s}$ and $\Delta \mathrm{E} / \mathrm{V}=0.130(A)$ and $1(B)$.

Figure 3 shows logarithmic analyses of responses to low scan rates. If the step duration $\tau$ is so long that the steady state is established before the current is measured, the response is defined by the following equation:

$$
\Phi=\{\exp (F \Delta E / 2 R T)-1] /[1+\exp (F \Delta E / 2 R T]
$$

This equation can be transformed into the logarithmic form:

$$
\left.E_{1}-E^{0}=0.059 \log [1+\Phi) /(1-\Phi)\right]
$$

The straight line (1) in Figure 3 satisfies eq. (24), but the curves (2) and (3) have lower slopes at the smallest potential difference. The curve (3) corresponds to the curve (4) in Figure 1 . One can notice that the latter current potential curve is steeper than the curve (5) in this figure. This is the reason of the lower slope in Figure 3. 


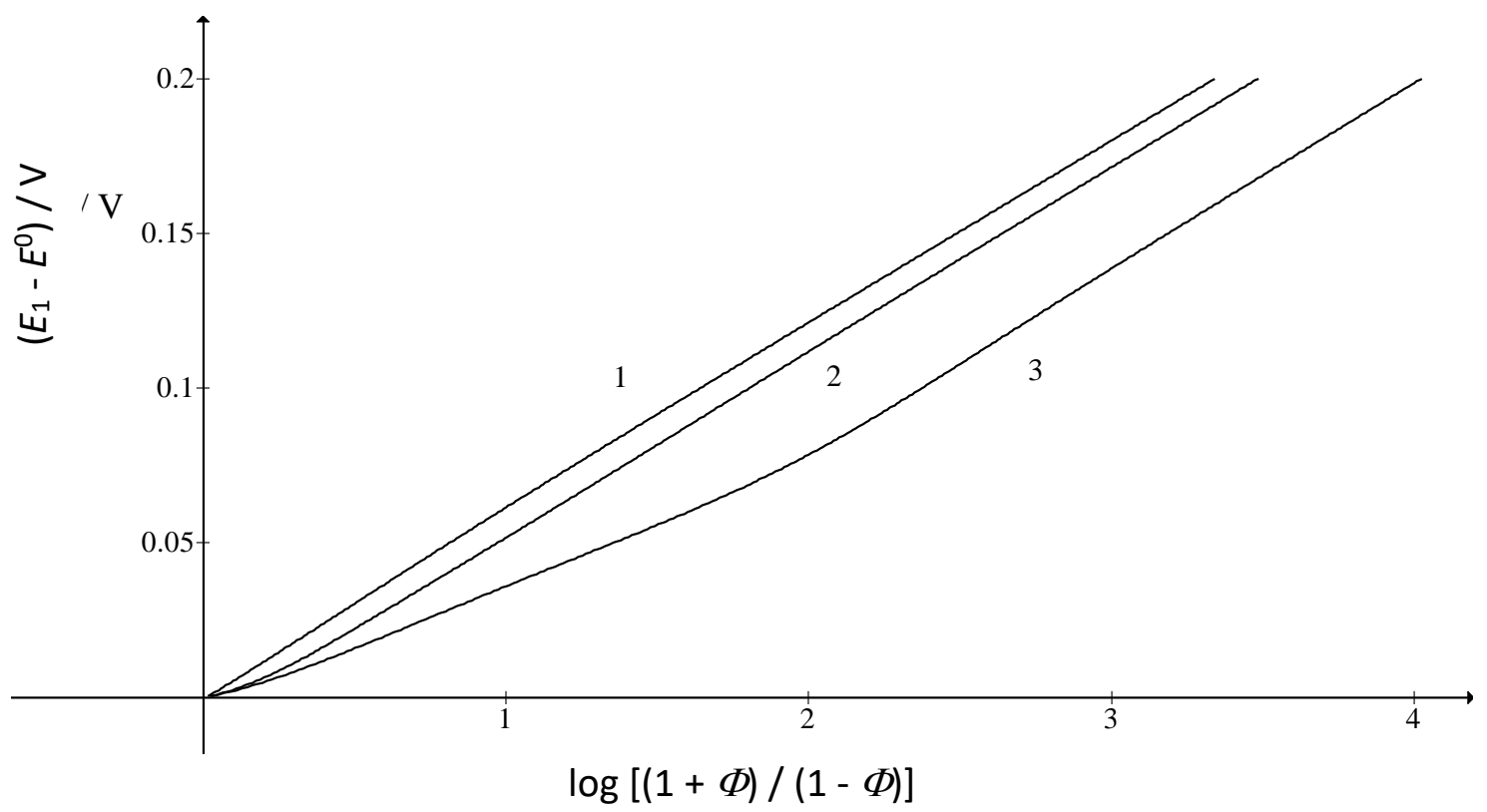

Fig. 3. Logarithmic analyses of the responses of electrode reaction (1). $[M X]^{*}=0$ and $\mathrm{v} / \mathrm{Vs}^{-1}=0.01(1), 0.1(2)$ and $0.2(3)$

Under transient conditions the responses are characterized by maxima. Figure 4A shows the relationship between the logarithms of peak current and scan rate. Black circles can be connected by the straight line (1):

$$
\log \Phi_{\max }=0.425 \log v+0.238
$$

This result is in agreement with the observation that the maximum develops before the diffusion layers are overlapped. The potentials of maxima increase with the increasing scan rate, as can be seen in Fig. 4B. The asymptote (1) is defined by the equation:

$$
\Delta E_{\max } / \mathrm{V}=0.144 \log v+0.086
$$

As the electrode reaction (1) is reversible, this relationship can be ascribed to the influence of $I R_{\Omega}$ drop.

Figure 5 shows voltammograms in the presence of various concentrations of supporting electrolyte. They differ in the properties of maxima. The peak current is the highest if $[\mathrm{MX}]^{*} / c_{\text {Red }}^{*}=10$ and it stagnates if this ratio is higher than 1000 . The potential difference of maximum is $0.068 \mathrm{~V}$ if $[\mathrm{MX}]^{*} / c_{\mathrm{Red}}^{*}>100$. These changes can be explained by the diminished $I R_{\Omega} \mathrm{drop}$. It seems that the contribution of migration is significant if the concentration of supporting electrolyte is low, but it vanishes in highly concentrated electrolytes.

These effects were investigated further by the variation of scan rate in fully supported systems. The results are presented in Figure 4, as black squares. Firstly, the peak potentials are independent of scan rate. Their average value is $0.074 \mathrm{~V}$, which is shown by the straight line (2) in Figure 4B. Furthermore, the peak currents can be approximated by the linear relationship (see the line (2) in Fig. 4A):

$$
\log \Phi_{\max }=0.454 \log v+0.255
$$

This slope is closer to 0.5 than the slope 0.425 that appears in the absence of supporting electrolyte.

The difference between these two slopes is ascribed to the $I R_{\Omega}$ drop. However, in the thin layer cell one cannot expect that the current depends on the square root of scan rate, as in the case of semi-infinite diffusion. These calculations show that the electrode reaction (1) is controlled only by the diffusion if the concentration of supporting electrolyte is thousand times higher than the concentration of the electroactive redox couple. This is in agreement with literature data $[1,6,10]$. 


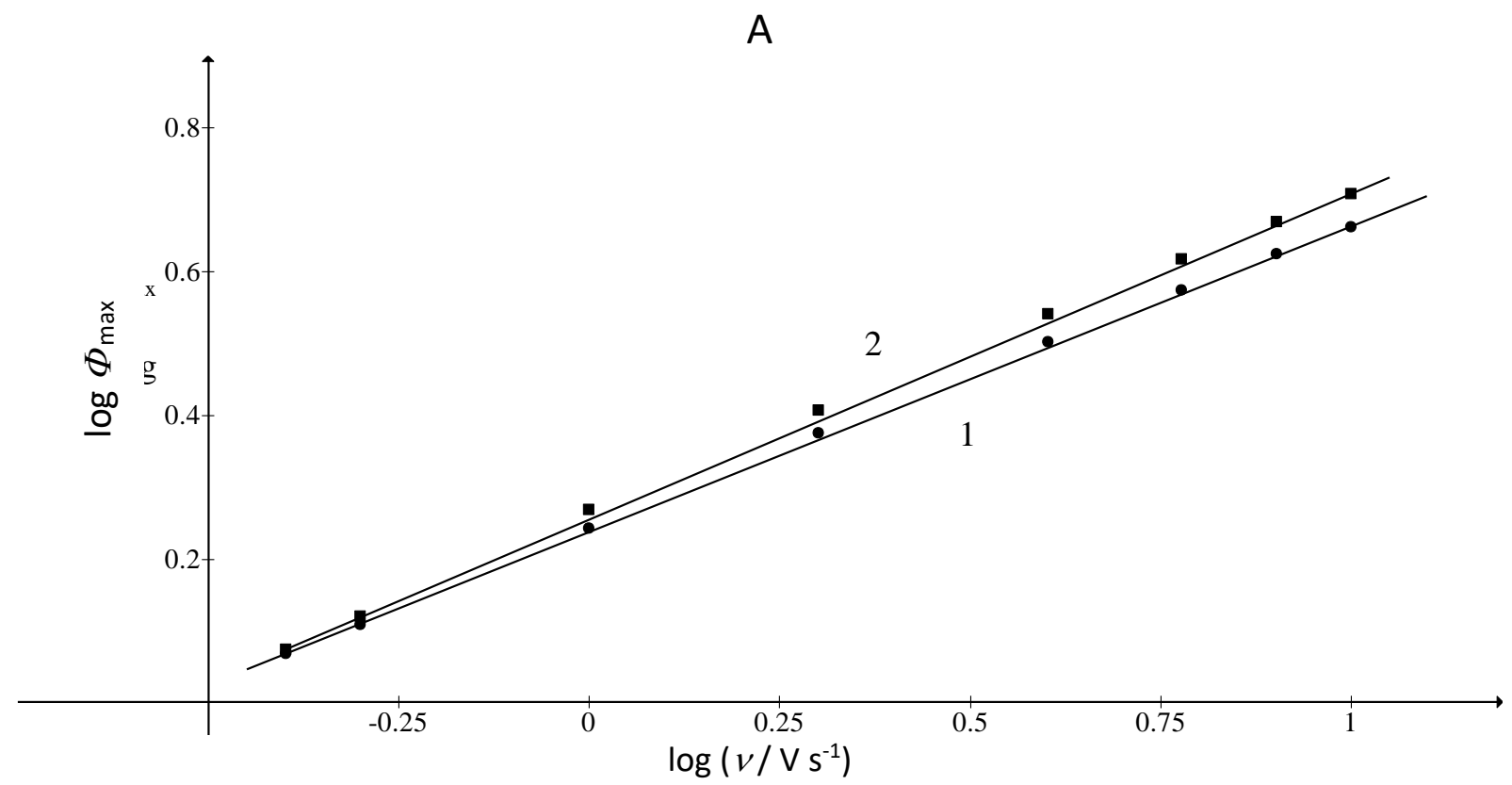

$B$

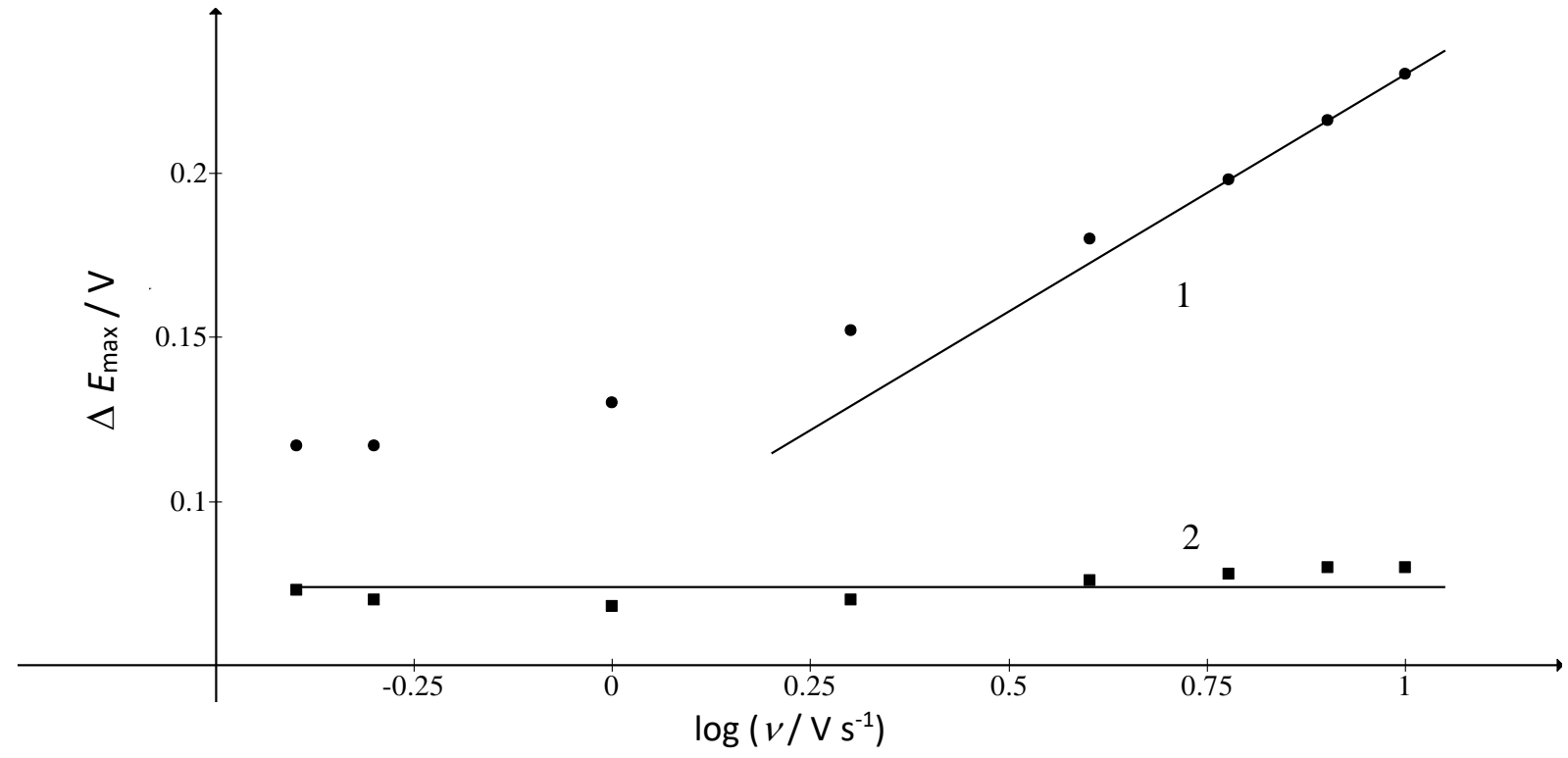

Fig. 4. Dependence of the logarithm of the maximum current $(A)$ and the potential difference of the maximum (B) on the logarithm of scan rate. $[M X]^{*} / c_{\text {Red }}^{*}=0(1)$ and $10^{3}(2)$. The straight lines are linear approximations

In the last part of this paper, the influence of the kinetics of electrode reaction is investigated. It is assumed that the supporting electrolyte is present in high concentration, so that the migration of electroactive cations can be neglected. Under these conditions eqs. (9) and (13) are replaced by the well-known Butler-Volmer equations. Some results are shown in Figure 6. Voltammograms depend on the normalized kinetic parameter $k_{\mathrm{s}}^{*}=\left(k_{\mathrm{s}} / l\right) / 100$, where $k_{\mathrm{s}}$ is the standard rate constant of electrode reaction, and on the transfer coefficient $\alpha$. If $I=50 \mu \mathrm{m}$, the constant $k_{\mathrm{S}}^{*}=10^{-3} \mathrm{~s}^{-1}$ corresponds to $k_{\mathrm{s}}=5 \times 10^{-4} \mathrm{~cm} \mathrm{~s}^{-1}$.

The main difference between Figure 6 and Figure 1 is the inflexion point at $0.2 \mathrm{~V}$ in Figure 6 . All curves in Figure 1 are convex between zero and the maximum, while in Figure 6 the curves start as concave. 


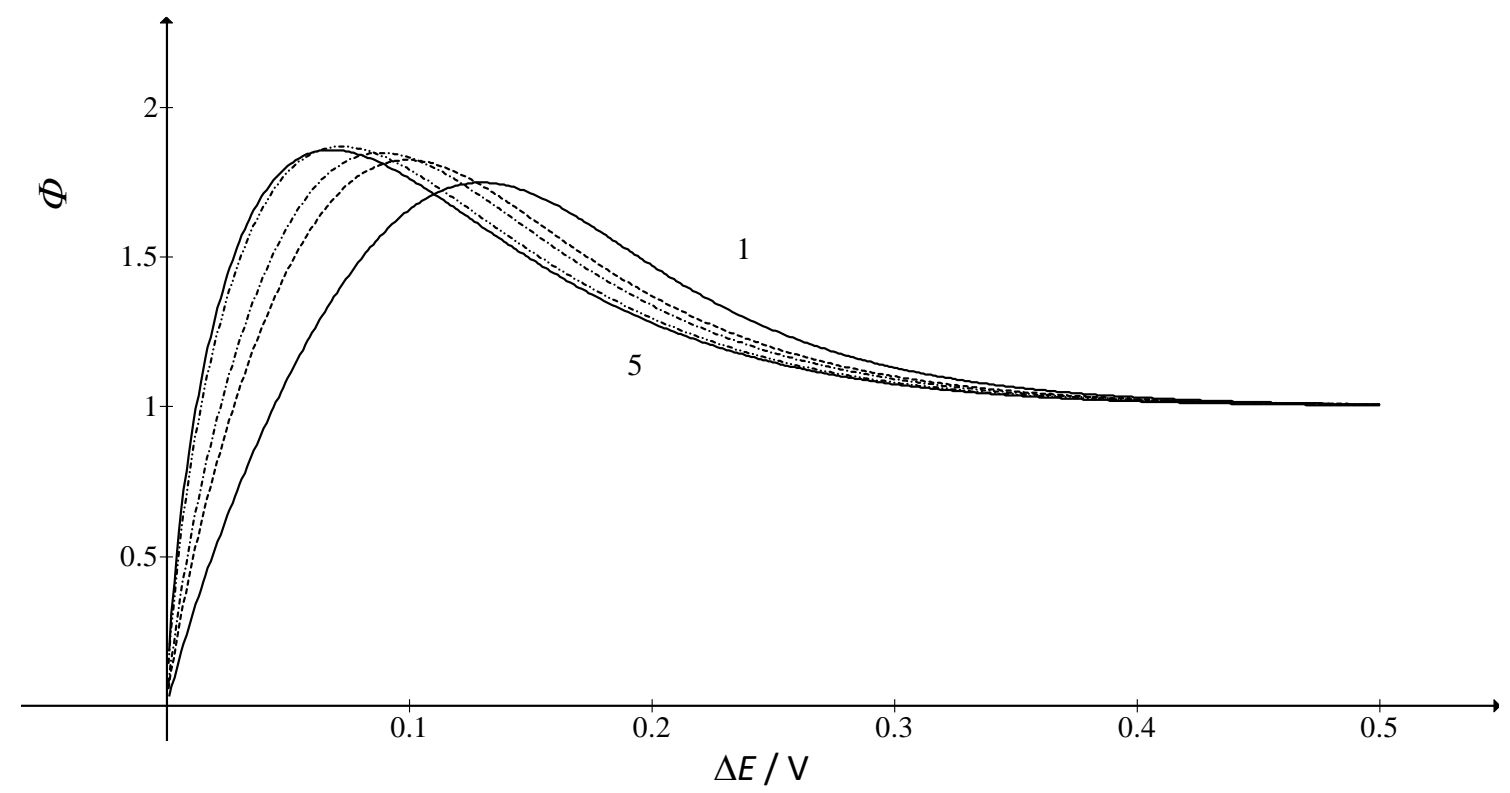

Fig. 5. Influence of the concentration of supporting electrolyte on the voltammograms of electrode reaction (1). $v=1 \mathrm{~V} / \mathrm{s}$ and $[\mathrm{MX}]^{*} / c_{\mathrm{Red}}^{*}=0(1), 1(---), 2(-.--), 10(-\ldots-.-)$ ) and 5000 (5)

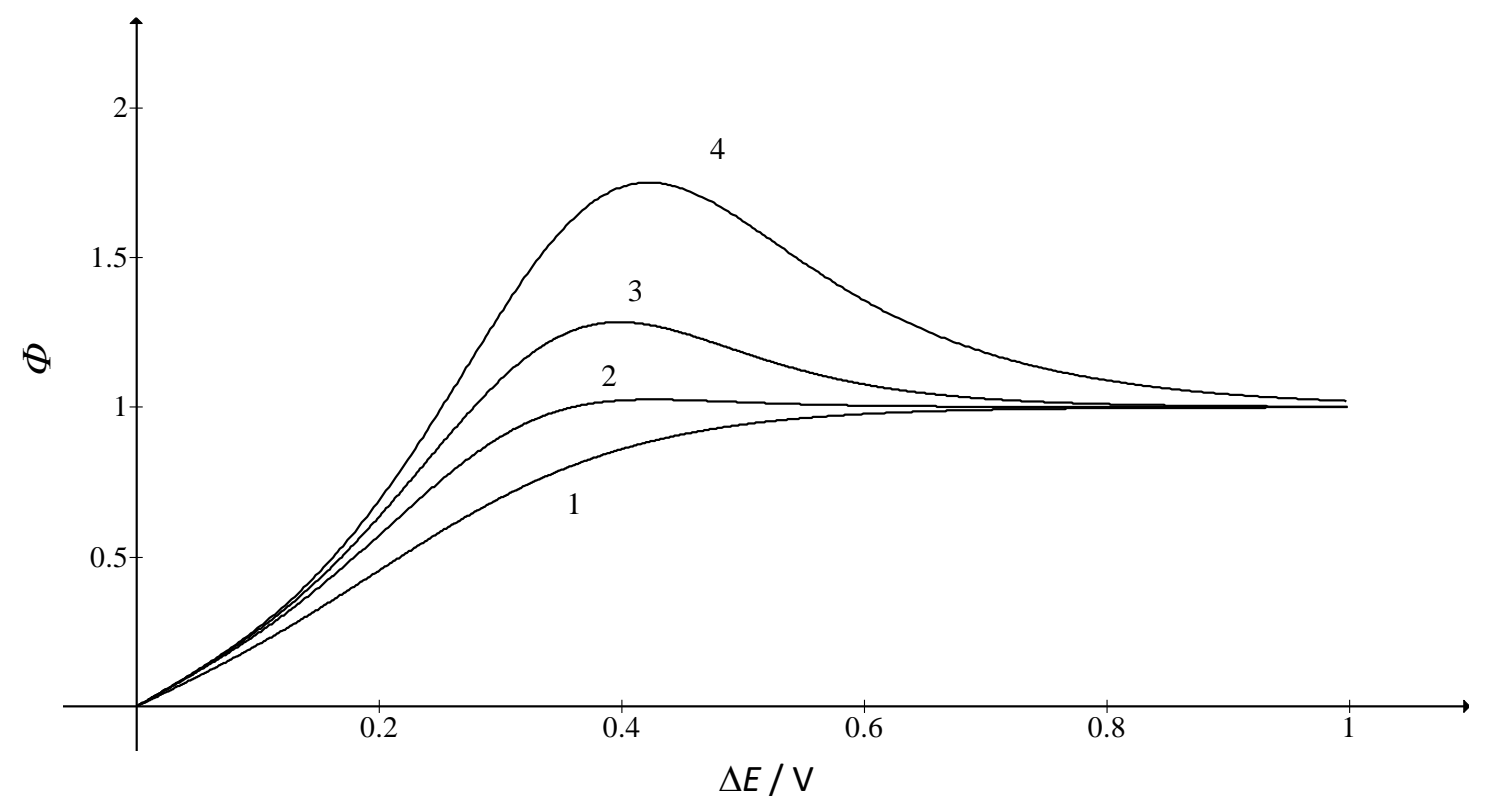

Fig. 6. Dimensionless staircase voltammograms of quasireversible electrode reaction (1) in a great excess of supporting electrolyte. $k_{\mathrm{S}}^{*}=10^{-3} \mathrm{~s}^{-1}, \alpha=0.5$ and $v / \mathrm{Vs}^{-1}=0.01$ (1), 0.5 (2), 1 (3) and 2 (4)

Figure 7 shows that this change of curvature has the consequence on logarithmic analyses. They all tend to the straight line with the slope of $0.118 \mathrm{~V}$ for $\alpha=0.5$. However, below $0.1 \mathrm{~V}$ all curves have slopes higher than the limiting one. The effect of too high scan rate is added to the kinetic effect.

The peak currents and peak potentials of voltammograms that are shown in Figure 6 satisfy the following relationships:

$$
\begin{aligned}
& \Phi_{\max }=0.47 \log v+0.10 \\
& \Delta E_{\max }=0.118 \log v+0.383
\end{aligned}
$$

The latter one can be used for the estimation of the transfer coefficient together with the logarithmic analysis. 


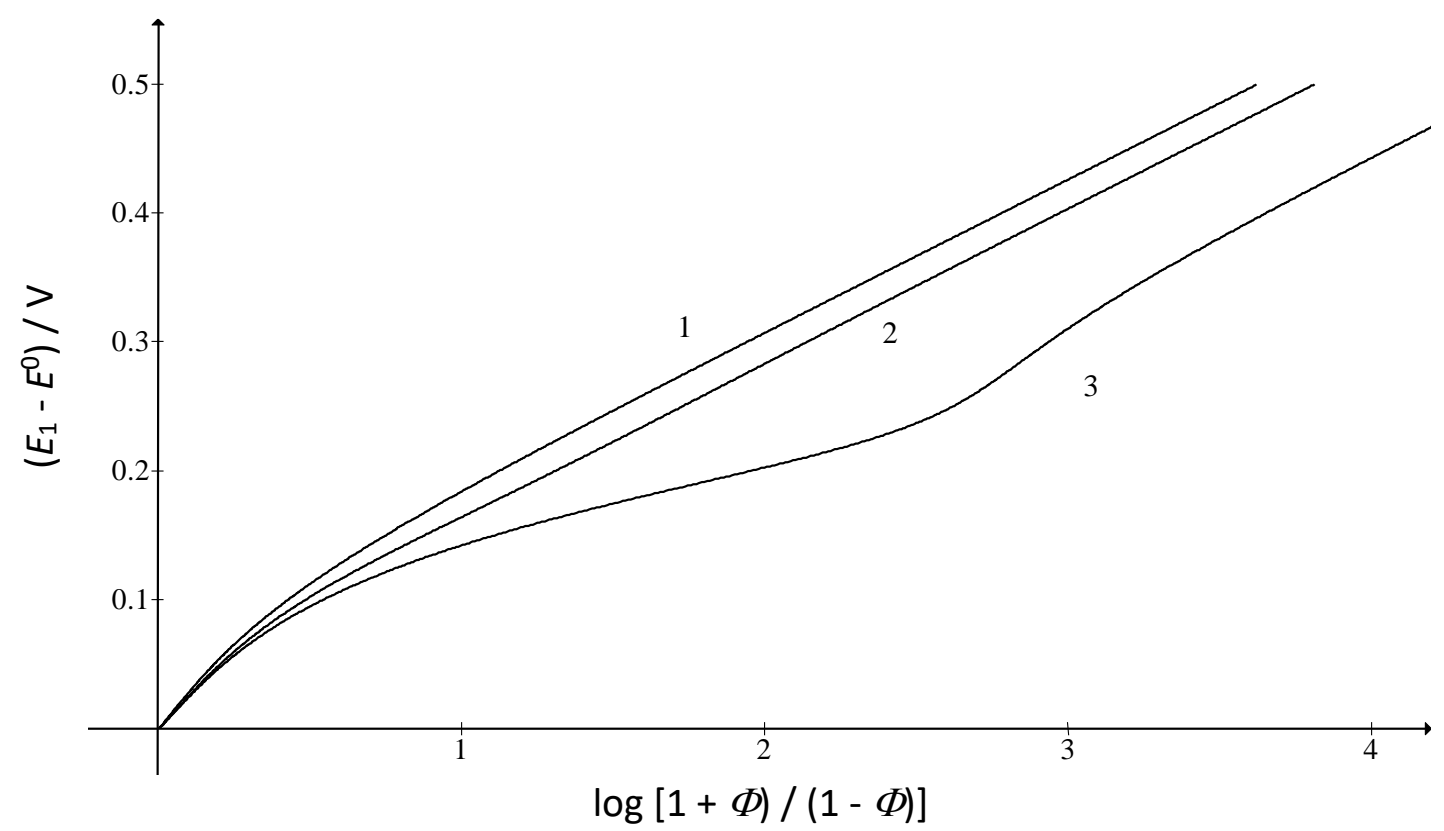

Fig. 7. Logarithmic analyses of responses of quasi-reversible electrode reaction (1). $k_{\mathrm{S}}^{*}=10^{-3} \mathrm{~s}$ $1, \alpha=0.5$ and $v / V s^{-1}=0.01$ (1), 0.2 (2) and 0.4 (3).

\section{Conclusions}

This simplified model shows that the staircase voltammetry can be applied to the electroactive redox couple in the twin electrode thin layer cell in the absence of supporting electrolyte. Under this condition the response is influenced by an $I R_{\Omega}$ drop. At high scan rates the voltammograms of reversible electrode reaction exhibit maxima. The potentials at which these maxima appear depend linearly on the logarithm of scan rate. In the presence of supporting electrolyte in very high concentration, the potentials of maxima are independent of scan rates. This is an evidence of reversible charge transfer.

Presented calculation show that under steady state conditions the concentration profile of ionic product is not linear because of migration. All responses tend to the limiting current that is caused by these concentration profiles.

If the electrode reaction is not reversible, but the $I R_{\Omega}$ drop can be neglected, the logarithmic analysis of the response recorded under steady state conditions is a curve that tends to the straight line with the slope equal to $R T$ / $\alpha F$. In the beginning of this curve, the slope is higher. The logarithmic analysis of the response of reversible electrode reaction is not a curve, but the straight line with the slope $R T / F$.

\section{References}

[1] N. P. C. Stevens, A. M. Bond, Journal of Electroanalytical Chemistry 538 - 539 (2002) 25-33.

[2] W. Hyk, A. Nowicka, Z. Stojek, Analytical Chemistry 74 (2002) 149-157.

[3] K. B. Oldham, Journal of Physical Chemistry B 104 (2000) 4703-4706.

[4] J. C. Myland, K. B. Oldham, Electrochemistry Communications 1 (1999) 467-471.

[5] G. A. Tsirlina, Journal of Solid State Electrochemistry 21 (2017) 1833-1845.

[6] E. J. F. Dickinson, J. G. Limon-Petersen, N. V. Rees, R. G. Compton, Journal of Physical Chemistry C 113 (2009) 11157-11171.

[7] I. Streeter, R. G. Compton, Journal of Physical Chemistry C 112 (2008) 13716-13728.

[8] K. Aoki, Electroanalysis 5 (1993) 627-639.

[9] N. P. C. Stevens, M. B. Rooney, A. M. Bond, S. W. Feldberg, Journal of Physical Chemistry A 105 (2001) 9085-9093. 
[10] V. M. Volgin, A. D. Davydov, Electrochimica Acta 259 (2018) 56-65.

[11] A. T. Hubbard, F. C. Anson, Analytical Chemistry 36 (1964) 723-726.

[12] C. R. Christiansen, F. C. Anson, Analytical Chemistry 35 (1963) 205-209.

[13] D. M. Oglesby, S. H. Omang, C. N. Reilley, Analytical Chemistry 37 (1965) 1312-1316.

[14] I. B. Goldberg, A. J. Bard, Journal of Electroanalytical Chemistry 38 (1972) 313-322.

[15] J. M. Saveant, Journal of Electroanalytical Chemistry 238 (1987) 1-8.

[16] C. N. Reilley, B. McDuffie, Analytical Chemistry 38 (1966) 1881-1887.

[17] J. C. Jernigan, C. E. Chidsey, R. W. Murray, Journal of American Chemical Society 107 (1985) 28242826.

[18] B. J. Feldman, A. G. Ewing, R. W. Murray, Journal of Electroanalytical Chemistry 194 (1985) 63-81.

[19] Š. Komorsky-Lovrić, M. Lovrić, Croatica Chemica Acta 64 (1991) 625-635.

[20] H. S. White, K. McKelvey, Current Opinion in Electrochemistry 7 (2018) 48-53.

[21] T. R. L. C. Paixao, E. M. Richter, J. G. A. Brito-Neto, M. Bertotti, Journal of Electroanalytical Chemistry 596 (2006) 101-108.

[22] C. Montella, Journal of Electroanalytical Chemistry 808 (2018) 348-361.

[23] A. W. Bott, Current Separations 16 (1997) 23-26.

[24] M. Lovrić, Š. Komorsky-Lovrić, To Chemistry Journal 1 (2018) 370-375.

[25] C. Batchelor-McAuley, E. Katelhon, E. O. Barnes, R. G. Compton. E. Laborda, A. Molina, ChemistryOpen 4 (2015) 224-260.

[26] C. Batchelor-McAuley, M. Yang, E. M. Hall, R. G. Compton, Journal of Electroanalytical Chemistry 758 (2015) 1-6.

[27] A. Molina, J. Gonzalez, Pulse Voltammetry in Physical Electrochemistry and Electroanalysis, Springer, Berlin, 2016.

[28] N. G. Connelly, W. E. Geiger, Chemical Reviews 96 (1996) 877-910.

[29] D. Britz, J. Strutwolf, Digital Simulation in Electrochemistry, Springer, Berlin, Germany, 2016.

C2019 by the authors; licensee IAPC, Zagreb, Croatia. This article is an open-access article distributed under the terms and conditions of the Creative Commons Attribution license (http://creativecommons. org/licenses/by/4.0/) 